This is the accepted manuscript, which has been accepted by IEEE for publication.

(C) 2009 IEEE. Personal use of this material is permitted. Permission from IEEE must be obtained for all other uses, in any current or future media, including reprinting/republishing this material for advertising or promotional purposes, creating new collective works, for resale or redistribution to servers or lists, or reuse of any copyrighted component of this work in other works. The full reference is:

\title{
A Performance Analysis of Re-conductoring An Overhead Line Structure
} K. Kopsidas and S. M. Rowland

IEEE Transactions on Power Delivery, Vol. 24, No. 4, (2009), pp. 2248-2256

DOI: 10.1109/TPWRD.2009.2021042 


\title{
A Performance Analysis of Re-conductoring An Overhead Line Structure
}

\author{
Konstantinos Kopsidas, Student Member IEEE, and Simon M. Rowland, Senior Member IEEE
}

\begin{abstract}
A holistic computational methodology is employed in this paper to present an analysis of the widely used aluminum alloy conductors (AAAC) performance on a 33-kV wood pole structure. This analysis highlights the basic system properties that influence its mechanical and electrical performance. A comprehensive comparison of the performance of the common AAAC and aluminum conductor steel reinforced (ACSR) conductors erected on the structure is presented, including the study of the increase in operating temperature on the losses, ampacity and sag, in order to identify the most appropriate conductor for the pre-specified structure. Some recently developed high temperature low sag (HTLS) composite conductors are also studied in terms of power transfer uprating on distribution overhead lines. Their performance is examined at normal temperatures instead of the high operating temperatures for which they are specifically designed for, in order to evaluate the benefits they may offer at distribution level voltages.
\end{abstract}

Index Terms-Aluminum alloy conductors (AAAC), aluminum conductor steel reinforced (ACSR), ampacity, high temperature, high-temperature low sag (HTLS), reconductoring, sag.

\section{INTRODUCTION}

$\mathbf{T}$ HE continuous growth in electrical power demand along with the competitive deregulated market have driven the utilities to face electric grid bottlenecks resulting in occasional brownouts and blackouts in recent years. As cost and environmental considerations present barriers to large investments in rebuilding existing lines and/or constructing new ones, electric utilities face a challenge to increase the power transfer capacity of existing overhead lines (OHL).

An overhead line's performance is limited by groundclearance and therefore sag. This presents an ampacity limit because of thermal expansion. Re-tensioning is considered to be an effectively economical method used to increase the capacity of an existing system by enabling existing lines to operate at higher temperatures. Another technique is reconductoring with conductors of larger size or of different type that allow higher temperature operation with less sag. These are usually referred to as high temperature low sag (HTLS) conductors. Either way, the computations for the new maximum current capacity (ampacity) and conductor sag have to be performed considering the OHL structure along with the

Manuscript received July 11, 2008; revised September 29, 2008. . This work was supported by the EPSRC Supergen V, U.K. Energy Infrastructure (AMPerES) Grant in collaboration with U.K. electricity network operators working under Ofgem's Innovation Funding Incentive scheme (http://www.supergenamperes.org). Paper no. TPWRD

The authors are with the School of Electrical and Electronic Engineering, The University of Manchester, Manchester, U.K. (e-mail: konstantinos.kopsidas@manchester.ac.uk; s.rowland@manchester.ac.uk).

Digital Object Identifier 10.1109/TPWRD.2009.2021042 conductor, which in some cases could limit its performance.

This paper employs the methodology described in [1] in a case study of the $33 \mathrm{kV}$ wood pole structure. The analysis and results initially involve the mechanical and electrical properties of all aluminum alloy conductors (AAAC). The performance of these conductors is then compared with aluminum conductor steel reinforced conductors (ACSR) and some newly developed HTLS composite conductors of equivalent sizes. The aim is to identify the improvement that re-conductoring may offer in the power transfer capacity of this OHL structure.

\section{CRITICAL LOADING CONDITIONS OF AN OHL}

Conductor sag and its clearance to the ground depend on the OHL system structure, the conductor electrical and mechanical properties, the environment, and operating conditions [1]. The critical operating conditions that develop the maximum sag are the maximum mechanical and electrical loading, one of which influences the designed minimum clearance to the ground and consequently, the power rating of the system.

The maximum mechanical loading of the OHL system (i.e. weather loading) influences the maximum conductor sag developed during the heavy weather conditions when the conductor is not electrically loaded. This occurs due to the increase of the conductor's resultant weight by wind and attached ice which affects the conductor's elastic and plastic elongation and stresses the conductor and the supporting structure, either of which can limit the system's performance. The weather loading determines the maximum conductor tension (MCT) which is influenced by the system strength, the self damping vibration limit tension and strength of the conductor [1]. This loading condition is calculated prior to electrical loading calculations as it is not influenced by the operating conditions (i.e. maximum conductor operating temperature) and defines the tension of the conductor at any other loading condition.

The maximum electrical loading of the OHL is influenced by the maximum mechanical loading of the line (i.e. MCT), the maximum operating temperature and power frequency, the ambient temperature and the properties of the conductor. These loading conditions determine the conductor sag, tension and ampacity at maximum operating conductor temperature ( $\left.\mathrm{T}_{\mathrm{OP}-\mathrm{MAX}}\right)$ and are limited by the minimum permitted clearance to the ground $[2,3]$ and the temperature at which the conductor suffers irreversible loss of strength [4].

\section{THE 33KV WoOd Pole System}

According to the methodology presented in [1], it is 
important to pre-define the variables that define the OHL structure and the weather loading as a description of the overall system in order to initiate the computations at the maximum loading conditions.

A typical $33 \mathrm{kV}$ single (stout) wood pole distribution line is used in this study (Fig. 1). The $33 \mathrm{kV}$ pin insulators that are used for the phase conductors are $24 \mathrm{~cm}$ in height [5] which is the minimum length for the medium pollution level according to the creepage distance $(20 \mathrm{~mm} / \mathrm{kV})$ for vertical insulators [6]. The insulator tension strength is $80 \mathrm{kN}$ and the minimum bending failing load for the insulator pin is $10 \mathrm{kN}(70 \mathrm{kN}$ tension load) [7]. The total height of the pin insulator and the pin with large steel head is taken as $45 \mathrm{~cm}[5,7]$. The overall structure meets the requirements of ENA Technical Specification [8].

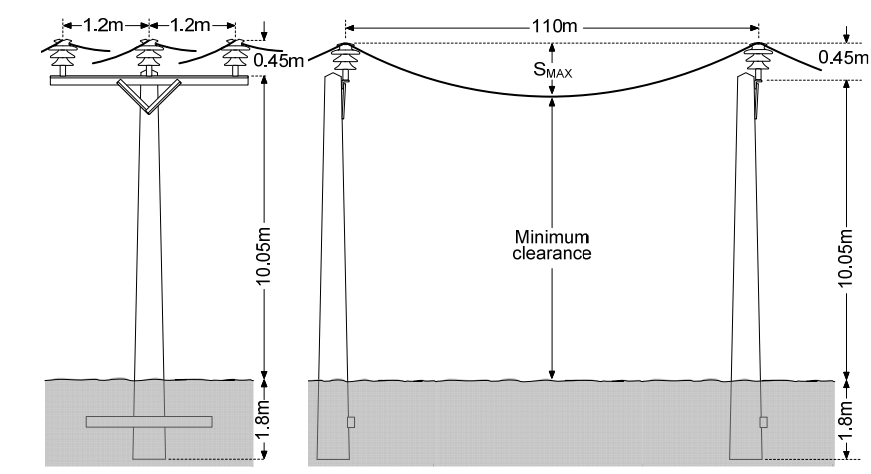

Fig. 1. Single wood pole $33 \mathrm{kV}$ distribution line diagram.

The weather conditions in which the OHL structure is installed are also part of the system specification and define the weather loading. The case of "normal" altitude loading is considered here, with a wind pressure of $380 \mathrm{~N} / \mathrm{m}^{2}$ and radial glaze ice thickness of $9.5 \mathrm{~mm}$ and $913 \mathrm{~kg} / \mathrm{m}^{3}$ density at -5.6 ${ }^{\circ} \mathrm{C}[8,9]$. Furthermore, the everyday tension (EDT), $20 \%$ rated breaking strength (RBS) for aluminum based conductors, is applied at the everyday temperature of $5^{\circ} \mathrm{C}$.

\section{Performance AnAlysis of AAAC ON THE 33KV SYSTEM}

\section{A. Maximum Mechanical Loading of AAACs}

The mechanical performance of selected AAAC conductors at the weather loading is calculated and the results of sag and MCT are illustrated in Table I. The MCT of the two smallest conductors is limited by their strength $(50 \% \mathrm{RBS})$, while the MCT for the two largest ones is limited by the OHL strength. The MCT for all other conductors is controlled by their self damping vibration limit tension [1].

The increase of the conductor size reduces the sag developed at extreme weather loading $\left(-5.6{ }^{\circ} \mathrm{C}\right)$ mainly due to the increase in conductor strength (Table I). A further increase of conductor size does not increase the MCT due to the OHL strength constraint [1]. This results in worse sagging performance since the increase in conductor size increases only the resultant weight of the conductor (Table I).

TABLE I

RESUltS AT WEATHER LOADING FOR DiFFERENT AAAC SizeS

\begin{tabular}{|c|c|c|c|c|c|c|}
\hline $\begin{array}{c}\text { Conductor } \\
\text { Code Name }\end{array}$ & $\begin{array}{c}\text { Diameter } \\
(\mathrm{mm})\end{array}$ & $\begin{array}{c}\text { Area } \\
\left(\mathrm{mm}^{2}\right)\end{array}$ & $\begin{array}{c}\mathrm{W}_{\mathrm{C}} \\
(\mathrm{kg} / \mathrm{km})\end{array}$ & $\begin{array}{c}\text { RBS } \\
(\mathrm{kN})\end{array}$ & $\begin{array}{c}\text { MCT } \\
(\mathrm{kN})\end{array}$ & $\begin{array}{c}\text { Sag } \\
(\mathrm{m})\end{array}$ \\
\hline ALMOND & 7.02 & 30.1 & 82.94 & 8.88 & 4.44 & 3.82 \\
\hline FIR & 8.85 & 47.8 & 131.78 & 14.11 & 7.055 & 2.63 \\
\hline HAZEL & 9.9 & 59.9 & 164.88 & 17.66 & 8.318 & 2.35 \\
\hline OAK & 14 & 118.9 & 327.44 & 35.07 & 13.09 & 1.82 \\
\hline MULBERRY & 15.9 & 150.9 & 423.12 & 44.52 & 15.363 & 1.69 \\
\hline ASH & 17.4 & 180.7 & 506.66 & 53.31 & 17.596 & 1.58 \\
\hline ELM & 18.8 & 211 & 591.53 & 62.24 & 19.853 & 1.49 \\
\hline POPLAR & 20.1 & 239.4 & 681.01 & 70.61 & 21.396 & 1.47 \\
\hline UPAS & 24.7 & 362.1 & 1030.2 & 106.82 & 23.333 & 1.65 \\
\hline YEW & 28.4 & 479 & 1362.8 & 141.31 & 23.333 & 1.92 \\
\hline
\end{tabular}

Fig. 2 illustrates how the conductor and OHL strength, and the resultant conductor weight affect the overall sag performance of an OHL system as the conductor size increases. The complexity of the model is reduced by neglecting the effect of the conductor stranding on its weight and tensile strength [10] in order to simplify the graph. This model consequently, applies for cylindrical conductors with constant tensile strength (i.e. it is independent of conductor diameter) [10-12].

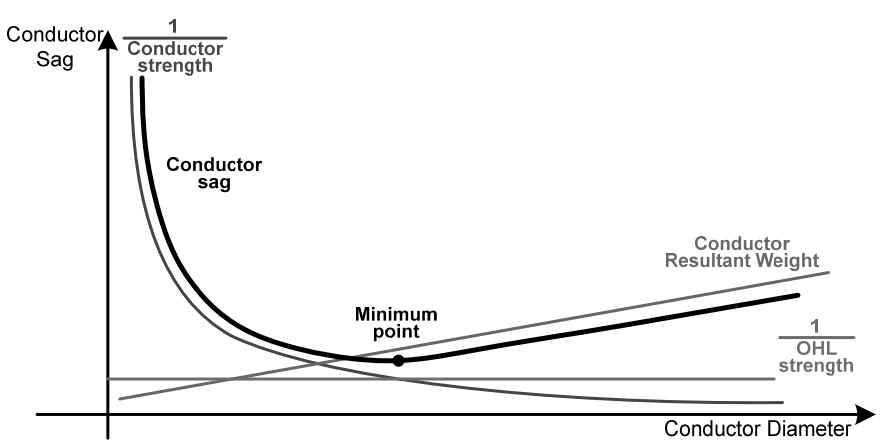

Fig. 2. Simplified model of factors affecting sag performance of solid conductors at weather loading conditions.

The minimum point (Fig. 2) corresponds to the conductor size that is located at the intersection of the conductor strength and OHL strength. Therefore, an increase of OHL structure strength shifts the minimum point towards lower sag values at bigger conductor diameters while an increase of conductor strength does the same at smaller diameters. The total conductor weight line determines the slope increase of the sag values at the right of the minimum point. For the $33 \mathrm{kV}$ system studied, Poplar is the conductor with the minimum sag (minimum point).

\section{B. Maximum Electrical Loading of AAACs}

The $\mathrm{T}_{\mathrm{OP}-\mathrm{MAX}}$ is set at $70{ }^{\circ} \mathrm{C}$ in this study as recommended by [2]. When higher operating temperatures are imposed the elevated temperature creep should also be considered; temperatures above $90{ }^{\circ} \mathrm{C}$ are avoided, though, due to annealing [4]. For simplicity, the ageing computations are omitted and, therefore, the conductors' DC and AC resistances along with the conductor ampacity $\left(\mathrm{I}_{\mathrm{MAX}}\right)$, tension (CT) and sag without creep are calculated at $70{ }^{\circ} \mathrm{C}$. Table II summarizes the results of the calculations at maximum electrical loading. The $\mathrm{dc}$ and ac conductor resistances are calculated according to [1], while standard input data are used for the ampacity calculations (e.g. emissivity, wind speed etc.) [13]. 
TABLE II

RESULTS AT MAXIMUM ELECTRICAL LOADING FOR DIFFERENT AAACS

\begin{tabular}{|c|c|c|c|c|c|c|}
\hline $\begin{array}{l}\text { Conductor } \\
\text { Code Name }\end{array}$ & $\begin{array}{c}\text { Diameter } \\
(\mathrm{mm})\end{array}$ & $\begin{array}{c}\mathrm{R}_{\mathrm{DC}-20^{\circ} \mathrm{C}} \\
(\Omega / \mathrm{km})\end{array}$ & $\begin{array}{l}\mathrm{R}_{\mathrm{AC}-70^{\circ} \mathrm{C}} \\
(\Omega / \mathrm{km})\end{array}$ & $\begin{array}{c}\mathrm{CT} \\
(\mathrm{kN})\end{array}$ & $\begin{array}{l}\text { Sag } \\
(\mathrm{m})\end{array}$ & $\begin{array}{c}\mathrm{I}_{\mathrm{MAX}} \\
(\mathrm{A})\end{array}$ \\
\hline ALMOND & 7.02 & \begin{tabular}{|l|}
1.0926 \\
\end{tabular} & 1.2893 & 0.356 & 3.46 & 123.2 \\
\hline FIR & $\varepsilon$ & & & 87 & 1 & 64.1 \\
\hline HAZEL & & & & 1.1 & 6 & 188.5 \\
\hline OAK & & & & 2.359 & 2.0 & 288.4 \\
\hline MULBERRY & 15.9 & 0.2192 & & 3.085 & 2.04 & 333.8 \\
\hline ASH & & & & 3.694 & 2.04 & 373.1 \\
\hline ELM & 18.8 & & 0.1853 & 4.31 & 2.04 & 410.4 \\
\hline POPLAR & & & & 4.945 & 2.04 & 443.3 \\
\hline UPAS & 24.7 & & & 5.907 & 2.59 & 571.4 \\
\hline YEW & 28.4 & 0.0693 & 0.0824 & 6.826 & 2.96 & 677.7 \\
\hline
\end{tabular}

The results of these computations (Table II) reveal how the sagging performance of the different conductors is affected by the limitations that apply to the system's MCT. Sag in turn, allows for the classification of the conductors into three different zones:

- Weak conductor zone: The sag performance of the conductor is driven by the conductor strength and its low strength is the main reason for high sagging. Within this zone, the conductor sag at maximum weather loading is larger than for maximum electrical loading.

- EDT (every day tension) zone: The sag performance of the conductor on the system is driven by the conductor self damping vibration limit. In homogeneous conductors the sag values within this zone are expected to be similar.

- Weak OHL zone: Conductor sagging is driven by the OHL structure strength limit. Further increase in diameter results only in an increase of conductor weight and as MCT is limited by the system, the sag therefore increases.

Fig. 3 illustrates the boundaries of these zones for both maximum weather and maximum electrical loading conditions (Tables I \& II). With this comparative presentation of the conductors' sagging performance on the OHL system the influence of the three zones described before is distinguishable. In particular, within the weak conductor zone the sag at weather loading is larger than the sag at the maximum electrical loading whereas within the other two zones the opposite occurs. Furthermore, the weak OHL zone is influenced in a similar way under both loading conditions (i.e. increase of sag) due to additional weight of the conductor and the limitation of the maximum installed tension by the strength of the OHL structure. Finally, in the EDT zone the sag developed due to electrical loading appears to be similar for all conductors. This is a result of the uniform structure of the AAAC and the conductor loading being influenced only by its properties (e.g. self damping vibration limit, thermal elongation) and not by the weather loading which does depend on the conductor size.

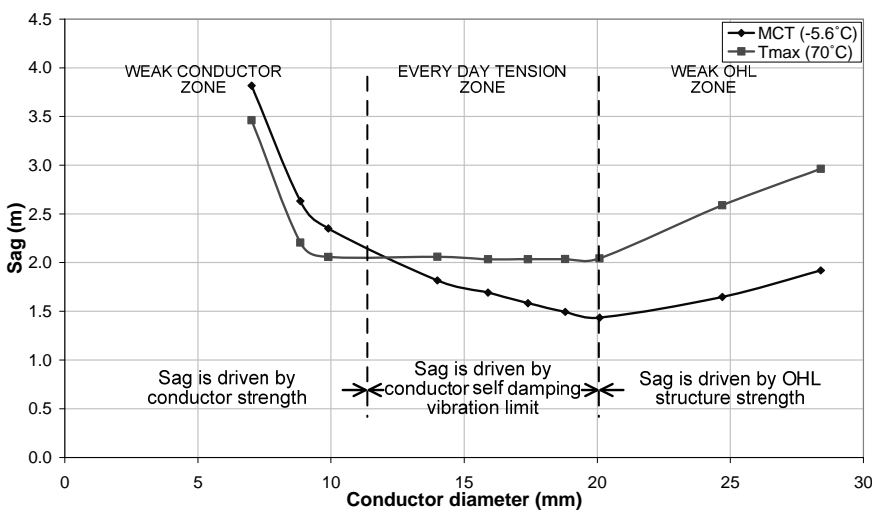

Fig. 3. The three zones of AAAC sag performance at maximum loading conditions.

The analysis of the electrical performance of AAACs on the OHL structure is simpler than the mechanical one since there are no limitations affecting the maximum electrical loading apart from the maximum operating temperature. This is the result of the height of the conductor attachment points set at $10.5 \mathrm{~m}$ which allows all the conductors to operate at 70 ${ }^{\circ} \mathrm{C}$ without infringing the minimum clearance to the ground $[2,3]$. Consequently, the bigger the conductor the higher the ampacity at $70{ }^{\circ} \mathrm{C}$, with Yew having the best electrical performance on the $33 \mathrm{kV}$ structure with ampacity around 680 A (Table II). The increase in $\mathrm{I}^{2} \mathrm{R}$ losses for the larger conductors is the result of the increase in ampacity, however, there is a reduction of the losses in percentage of the maximum power transfer of the line (Fig. 4).

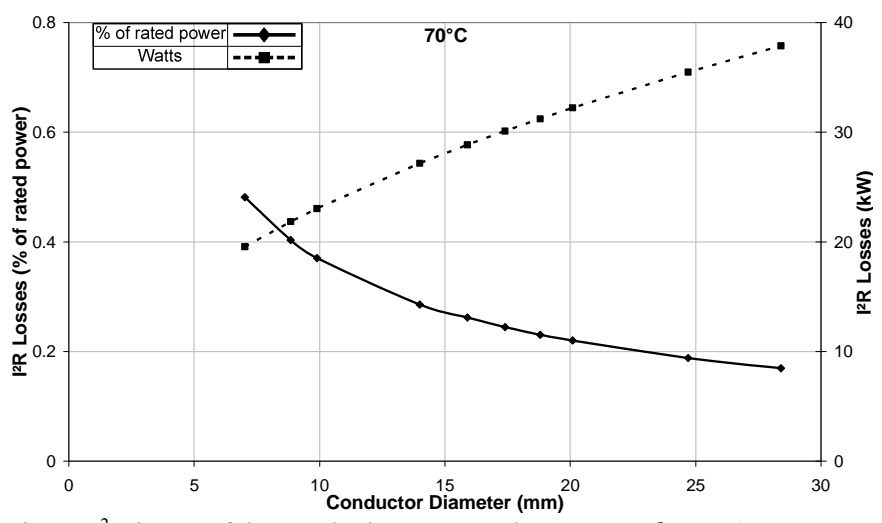

Fig. 4. $I^{2} \mathrm{R}$ losses of the standard AAAC conductors at $70{ }^{\circ} \mathrm{C}\left(\mathrm{T}_{\mathrm{OP}}\right)$.

The analysis of the system's electrical performance becomes more complex when the minimum clearance to the ground is infringed due to a shorter wood pole structure. In this case the maximum operating temperature of the conductor is controlled by the maximum conductor sag allowance, limiting the ampacity of the conductor. In order to illustrate this effect a maximum sag allowance of $2.2 \mathrm{~m}$ is assumed.

Fig. 5 shows the variation in sag for the various conductors at different operating temperatures. The conductors within the weak zone (Almond, Fir, and Hazel) are not suitable for the structure since they develop larger sags during the weather loading infringing the $2.2 \mathrm{~m}$ limit. The maximum operating temperature of the different conductors within the EDT zone (Oak to Poplar) that results in $2.2 \mathrm{~m} \mathrm{sag}$ is about $80^{\circ} \mathrm{C}$. This drops to less than $60{ }^{\circ} \mathrm{C}$ for Upas and less than $40{ }^{\circ} \mathrm{C}$ for the Yew conductor (Fig. 5). 


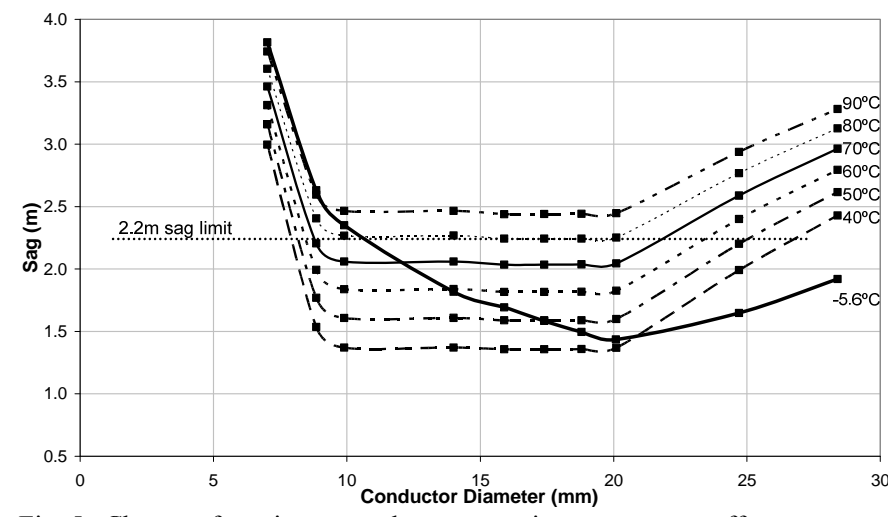

Fig. 5. Change of maximum conductor operating temperature effect on sag.

At $80{ }^{\circ} \mathrm{C}$, Poplar allows the highest power transfer through the $33 \mathrm{kV}$ structure with $526 \mathrm{~A}$ ampacity while the largest Upas performs worse allowing only 300 A current through the $33 \mathrm{kV}$ structure (Fig. 6). Yew conductor has proven too large for the structure infringing the $2.2 \mathrm{~m}$ sag even with no current flow as shown in Figs. 5 and 6.

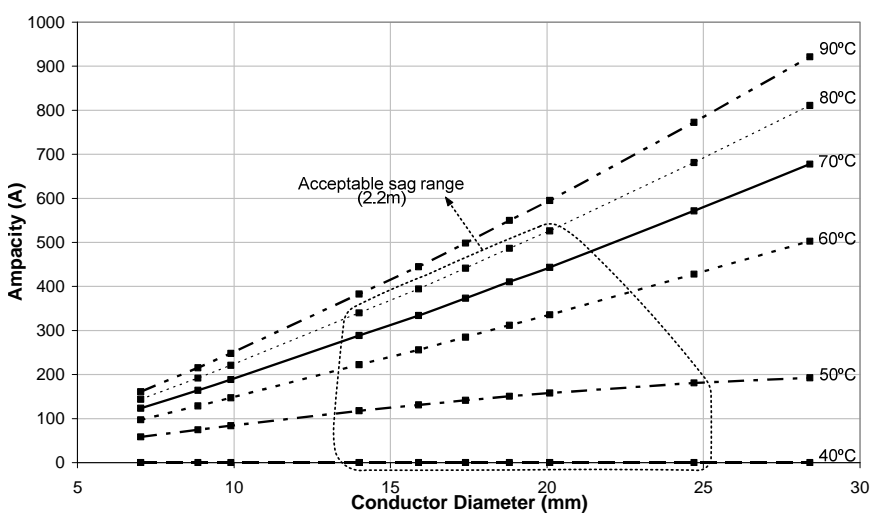

Fig. 6. Change of maximum conductor operating temperature effect on ampacity.

Changes in the maximum operating temperature influence the performance of AAACs during the maximum electrical loading. This changes the boundary between the weak conductor and the EDT zones, whereas it does not affect the one between the EDT and weak OHL zones. This boundary is only affected by the strength of the OHL. From Fig. 5 it can be seen that at $90{ }^{\circ} \mathrm{C}$ there is no weak conductor zone while at $40{ }^{\circ} \mathrm{C}$ the EDT zone overlaps with the weak conductor zone.

When the $2.2 \mathrm{~m}$ sag limit is considered, a different conductor appears to be most suitable (Poplar) for the OHL structure than the one initially found (Yew). This could be the case for shorter wood pole structures making the study more complex since the maximum electrical loading would be limited by the maximum sag. This assumption furthermore, illustrates the importance of considering the overall system in these calculations.

It is also important to note that the conductor's creep-strain effect is not considered here in order to simplify the study. In some practical cases this is not required because increased initial tension is applied to negate the creep-strain effect.

\section{V.COMPARISON OF ACSR AND AAAC PERFORMANCE}

\section{A. Comparison at Maximum Mechanical and Electrical Loading}

Several typical ACSR conductors are compared with the equivalent in size AAACs at maximum weather and electrical loading on the $33 \mathrm{kV}$ wood pole structure. Since ACSR conductors have bimetallic structure they are separated into soft and hard according to their steel-to-aluminum ratio. This helps the comparison as the mechanical and electrical properties are considerably affected by the conductor structure. For example, Horse and Dog conductors have similar cross-area but the former is roughly $40 \%$ stronger and heavier, and $25 \%$ more resistive than the latter (Table III).

The comparison of the sagging performance at the maximum mechanical (continuous lines) and electrical (dotted lines) loading of the ASCRs (soft and hard) and AAACs is illustrated in Fig. 7.

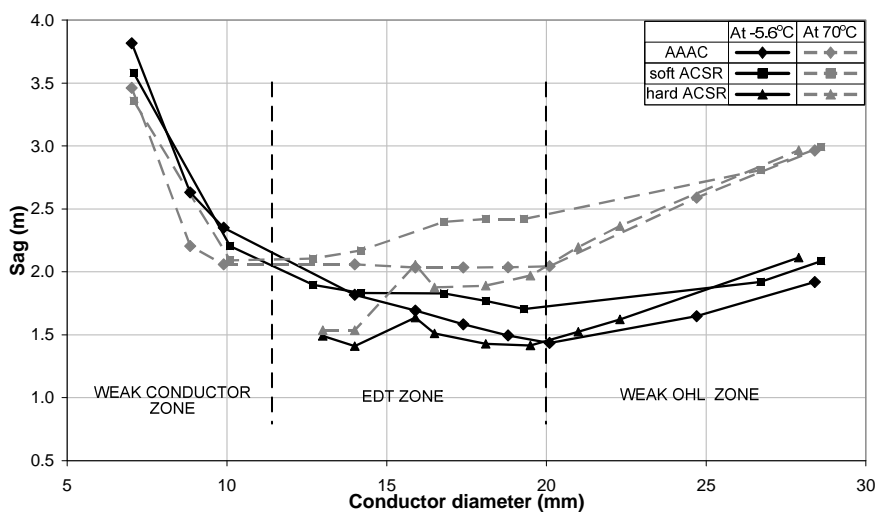

Fig. 7. AAAC and ACSR sagging performance at maximum weather and electrical loadings.

The maximum mechanical loading of the different ACSR conductors (Table III) is similar to the behavior described in Fig. 2. However, the different material composition of the hard ACSRs, soft ACSRs, and AAACs influences their strength and density and hence affects their sag performance. A simplified model of the effect of conductor strength and density on the sag performance caused by the difference in material composition is shown in Fig. 8 by contrasting steel and aluminium. The minimum point (of Fig.2) shifts towards smaller conductor diameters for the stronger material (steel) and the increase in sag after this point is faster compared to the weaker and lighter material.

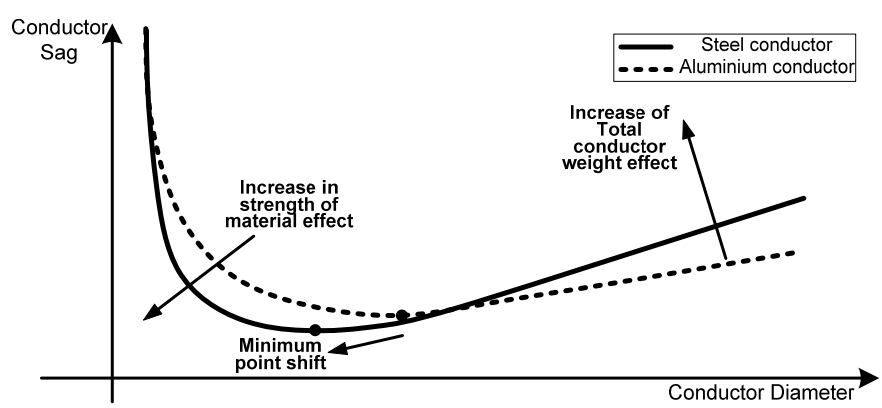

Fig. 8. Effect of strength and density on conductor sag for an OHL system at maximum loading conditions.

The inconsistent changes of sag values seen within the EDT zone in Fig. 7 (Coyote and Dingo conductors) are 
caused by the non-uniform composition of the bimetallic conductors over the range of sizes as well as by their different stranding patterns.

Fig. 7 also shows that hard ACSRs develop smaller sags in the mid-range sizes while AAACs have the best performance for conductors with diameter of $20 \mathrm{~mm}$ and bigger. Generally the soft ACSRs do not perform better than the AAACs when applied on the $33 \mathrm{kV}$ OHL structure. This could be due to the short span length or the relatively weak OHL structure.

The performance of ACSRs at maximum electrical loading is computed based on [1]. Results for conductor resistance, tension, sag and ampacity are presented in Table III. Fig. 7 illustrates the sagging performance at these operating conditions (dotted lines) of the three different conductor types and their zones of influence. The variations in sag performance of the ACSR conductors are caused again by the inconstant steel-to-aluminium ratio structure of conductors of this type as well as by the stranding effect. These variations are more marked for the hard ACSRs.

Within the EDT zone, hard ACSRs develop less sag compared to the AAACs whereas some soft ACSRs have similar, and some others worst sagging performance. The weak conductor zone is the same for AAACs and soft ACSRs (there are no hard ACSRs with such a small diameter) since small conductors do not have room for large changes in strength, therefore, they have similar sag performance.

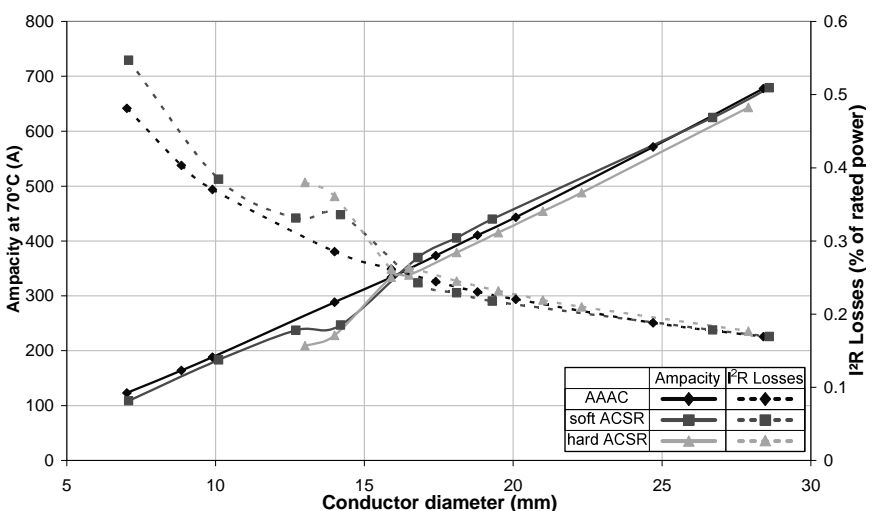

Fig. 9. Ampacity and $\mathrm{I}^{2} \mathrm{R}$ losses of AAACs and ACSRs at $70^{\circ} \mathrm{C}$.

The nonuniform steel content of the ACSR conductors within the range of these sizes affects their electrical resistance which, in turn, influences the ampacity and $I^{2} R$ losses of the conductors as shown in Fig. 9. The overall ampacity performance of the AAACs is very similar to the soft ACSRs with the exception of the two mid range conductors. However, AAACs develop less sag than the soft ACSRs which allows either operating the AAAC at higher temperatures or using a larger size on the same structure. Being lighter than the hard ACSRs results in the AAACs imposing reduced stress on the OHL structure. 
TABLE III

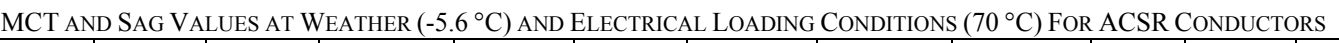

\begin{tabular}{|c|c|c|c|c|c|c|c|c|c|c|c|}
\hline $\begin{array}{c}\text { Conductor } \\
\text { Code Name }\end{array}$ & $\begin{array}{c}\mathrm{d} \\
(\mathrm{mm})\end{array}$ & $\begin{array}{c}\text { Area } \\
\left(\mathrm{mm}^{2}\right)\end{array}$ & $\begin{array}{c}\mathrm{W}_{\mathrm{C}} \\
(\mathrm{kg} / \mathrm{km})\end{array}$ & $\begin{array}{c}\mathrm{RBS} \\
(\mathrm{kN})\end{array}$ & $\begin{array}{c}\mathrm{MCT} \\
(\mathrm{kN})\end{array}$ & $\begin{array}{c}\text { Sag-5. }{ }^{\circ} \mathrm{C} \\
(\mathrm{m})\end{array}$ & $\begin{array}{c}\mathrm{R}_{\mathrm{DC}-20}{ }^{\circ} \mathrm{C} \\
(\Omega / \mathrm{km})\end{array}$ & $\begin{array}{c}\mathrm{R}_{\mathrm{AC}-70}{ }^{\circ \mathrm{C}} \\
(\Omega / \mathrm{km})\end{array}$ & $\begin{array}{c}\mathrm{CT} \\
(\mathrm{kN})\end{array}$ & $\begin{array}{c}\text { Sag } \\
(\mathrm{m})\end{array}{ }^{\circ} \mathrm{C}$ & $\begin{array}{c}\mathrm{I}_{\mathrm{MAX}} \\
(\mathrm{A})\end{array}$ \\
\hline GOPHER & 7.08 & 30.6 & 106.76 & 9.58 & 4.79 & 3.58 & 1.068 & 1.6586 & 0.47 & 3.36 & 108.8 \\
\hline RABBIT & 10.1 & 61.7 & 215.03 & 18.42 & 9.11 & 2.2 & 0.5301 & 0.6916 & 1.52 & 2.09 & 183.4 \\
\hline OTTER & 12.7 & 97.9 & 341.22 & 28.81 & 12.13 & 1.9 & 0.334 & 0.4606 & 2.41 & 2.1 & 237.3 \\
\hline SKUNK & 13 & 100.1 & 472.61 & 52.79 & 16.39 & 1.49 & 0.4237 & 0.5997 & 4.56 & 1.54 & 209.1 \\
\hline HORSE & 14 & 116.2 & 548.45 & 61.26 & 18.38 & 1.41 & 0.3652 & 0.5225 & 5.3 & 1.54 & 228 \\
\hline DOG & 14.2 & 118.5 & 396.4 & 32.65 & 13.42 & 1.83 & 0.2723 & 0.4493 & 2.71 & 2.17 & 246.7 \\
\hline COYOTE & 15.9 & 151.8 & 530.85 & 45.86 & 16.52 & 1.64 & 0.2148 & 0.2585 & 3.83 & 2.06 & 334.1 \\
\hline TIGER & 16.5 & 161.9 & 616.81 & 57.87 & 18.75 & 1.51 & 0.2136 & 0.2571 & 4.88 & 1.88 & 337.9 \\
\hline DINGO & 16.8 & 167.5 & 514.99 & 35.87 & 15.04 & 1.83 & 0.18 & 0.2166 & 3.19 & 2.4 & 369.7 \\
\hline CARACAL & 18.1 & 194.5 & 598.06 & 40.74 & 16.53 & 1.77 & 0.155 & 0.1866 & 3.67 & 2.42 & 405.3 \\
\hline WOLF & 18.1 & 194.9 & 742.9 & 68.91 & 21.57 & 1.43 & 0.1773 & 0.2136 & 5.83 & 1.89 & 378.9 \\
\hline JAGUAR & 19.3 & 222.3 & 683.79 & 46.57 & 18.17 & 1.7 & 0.1356 & 0.1633 & 4.19 & 2.42 & 439.9 \\
\hline LYNX & 19.5 & 226.2 & 862.03 & 79.97 & 23.33 & 1.42 & 0.1528 & 0.1842 & 6.49 & 1.97 & 415.3 \\
\hline PANTHER & 21 & 261.5 & 996.72 & 92.46 & 23.33 & 1.52 & 0.1322 & 0.1594 & 6.73 & 2.2 & 454.2 \\
\hline LION & 22.3 & 293.9 & 1119.93 & 100.47 & 23.33 & 1.62 & 0.1176 & 0.1420 & 7.03 & 2.36 & 488 \\
\hline ANTELOPE & 26.7 & 422.6 & 1460.09 & 118.88 & 23.33 & 1.92 & 0.076 & 0.0942 & 7.72 & 2.81 & 624.9 \\
\hline SHEEP & 27.9 & 462.6 & 1763.1 & 156.3 & 23.33 & 2.11 & 0.0747 & 0.0907 & 8.82 & 2.97 & 643.3 \\
\hline ZEBRA & 28.6 & 484.5 & 1673.9 & 131.92 & 23.33 & 2.09 & 0.0663 & 0.0824 & 8.31 & 2.99 & 679 \\
\hline \multicolumn{3}{|c|}{ hard ACSR: in bold } \\
\hline
\end{tabular}

\section{B. Analysis of Performance at Different Maximum Electrical Loading Temperatures}

To examine the effect of the conductor operating temperature on ampacity, losses and sag, different temperatures were used ranging from $50{ }^{\circ} \mathrm{C}$ to $100{ }^{\circ} \mathrm{C}$ while the still-air temperature remained constant at $40{ }^{\circ} \mathrm{C}$ [2]. Figs. 10, 11 and 12 compare the performance of AAACs with ACSRs of similar sizes.

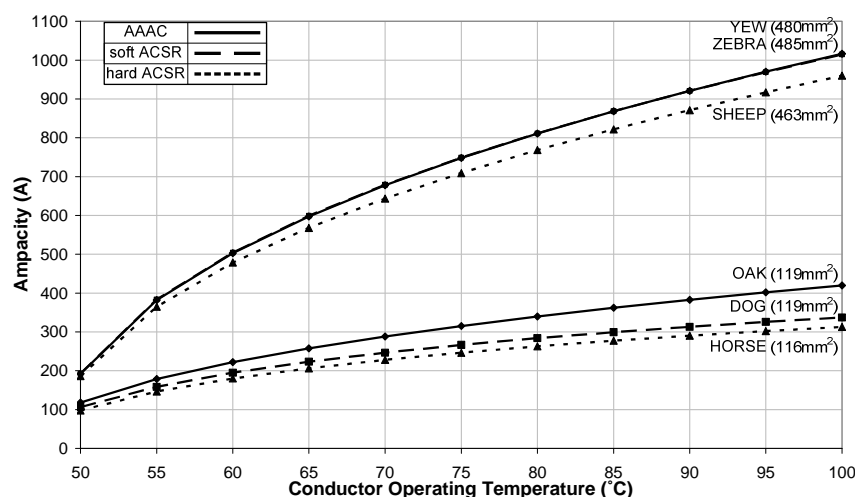

Fig. 10. Effect of $\mathrm{T}_{\mathrm{OP}-\mathrm{MAX}}$ on ampacity for different AAAC and ACSR sizes.

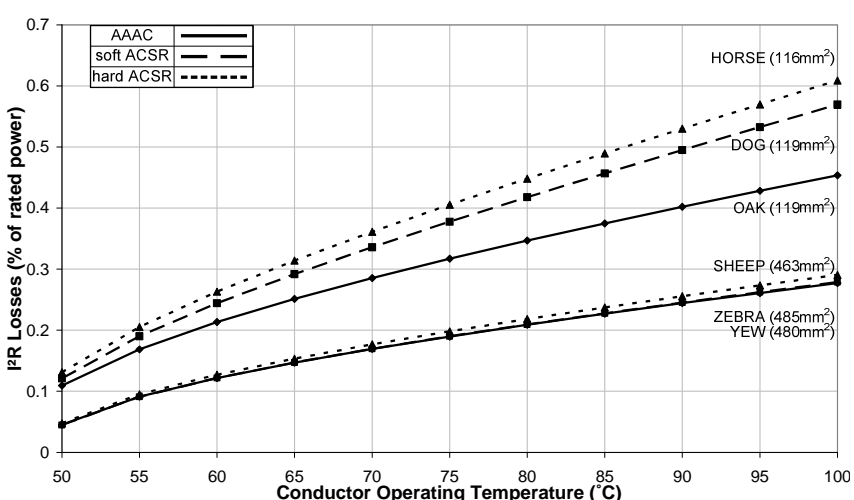

Fig. 11. Effect of $\mathrm{T}_{\mathrm{OP}-\mathrm{MAX}}$ on $\mathrm{I}^{2} \mathrm{R}$ losses for different $\mathrm{AAAC}$ and ACSR sizes

The increase in operating temperature allows a sublinear increase in current to flow through the conductors. This is a result of the increase of conductor resistance with the temperature rise, reducing the rate of increase in ampacity at higher temperatures. The ACSR conductors have lower ampacities and generate more losses than the AAACs, especially when their diameter is small. However, as the size of the conductor increases this difference in performance is reduced (Figs. 10 and 11). Furthermore, large conductors benefit more by the increase in operating temperature, compared to small ones, since their reduced resistance lowers the $I^{2} R$ losses in percentage terms and permits a larger increase in ampacity with smaller increase in conductor temperature.

The sag performance of AAAC conductors is influenced slightly more by the conductor operating temperature, when compared to the performance of ACSRs due to a higher coefficient of thermal expansion (Fig. 12).

The results of the maximum mechanical and electrical loading presented in this section do not include the conductor 
creep strain and they address the practical case that overtension is initially used to negate the creep-strain effect. It is also important to emphasize that the creep strain effect influences these values and particularly those for AAACs [4].

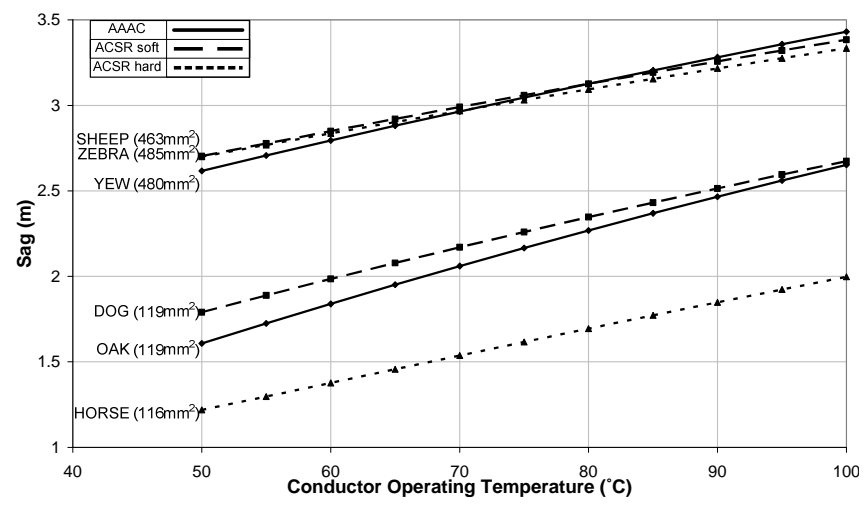

Fig. 12. Operating temperature effect on sag of AAAC and ACSR.

\section{Effect of Creep-Strain ( $($ ) on AAAC and ACSR Conductors}

The permanent increase of conductor length over time (creep strain effect) is affected by the operating temperature and tension history. The modeling of this plastic elongation is not a simple procedure since it is based on the prediction of the operating conditions for a long period of time $[1,4,14$, 15]. These conditions include the maximum weather and electrical loading, the designed conductor EDT at everyday temperature and the predicted duration of these three different conditions (Table IV).

TABLE IV

INPUT DATA FOR THE 10 YEAR CREEP-STRAIN MODELING COMPUTATION

\begin{tabular}{|c|c|c|c|c|}
\hline Loading & Tension & Temperature & \multicolumn{2}{|c|}{ Duration } \\
\cline { 4 - 5 } Conditions & (\%RBS) & ( $\left.{ }^{\circ} \mathbf{C}\right)$ & (Hours) & (\%) \\
\hline Everyday tension & $\begin{array}{c}\text { Calculated as } \\
\text { in [1] }\end{array}$ & 5 & 85848 & 98 \\
\hline $\begin{array}{c}\text { Maximum operating } \\
\text { temperature }\end{array}$ & CT & 70 & 876 & 1 \\
\hline $\begin{array}{c}\text { Maximum weather } \\
\text { loading }\end{array}$ & MCT & -5.6 & 876 & 1 \\
\hline
\end{tabular}

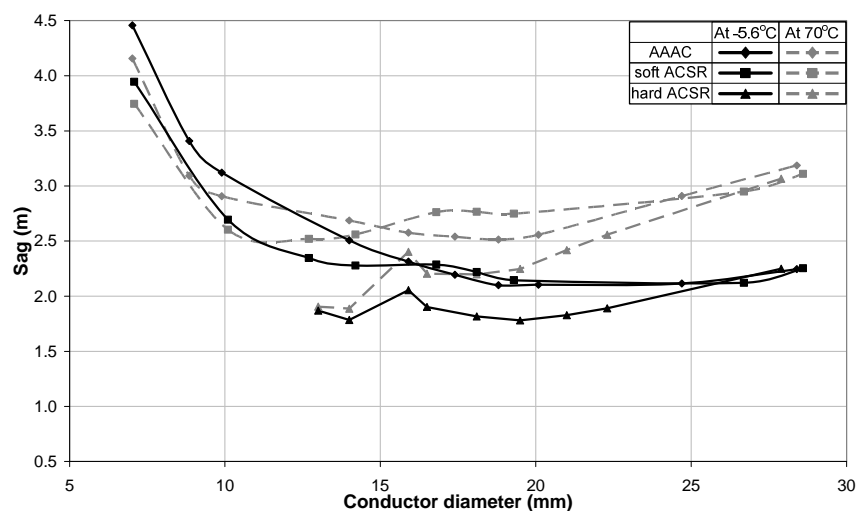

Fig. 13. Effect of ten-year creep $(\varepsilon)$ on the different conductor types and sizes.

The operating conditions in Table IV are used for the 10year creep strain prediction. It is assumed that for $1 \%$ of this time the conductor will operate at the designed hightemperature, for another $1 \%$ it will operate at the heavy weather loading condition and for $98 \%$ of the time it will operate at the EDT designed conditions. No pre-stressing is considered, and hence the plastic elongation consists of two components: the strand settlement and deformation and the "metallurgical" creep elongation. Fig. 13 presents the sag values of the different conductors developed at both maximum loading conditions after 10 years.

The comparison of the sag performance with creep of the three conductor types shows that less sag is developed on the hard ACSRs. By comparing Figs. 7 and 13 it can be seen that the larger the conductor the less the creep. This is mainly a result of the MCT reduction and the fact that the maximum weather loading dominates the creep effect. However, for the smaller conductors, the creep is less than that of conductors within the EDT zone since the reduction of diameter lowers the weather loading. This results in the EDT conditions controlling the conductor creep instead of the weather loading.

After including the creep-strain effect, the difference between the three different zones of conductor's sag is reduced dramatically for AAACs and ACSRs. It can also be seen that the creep influences the aluminium conductors more as expected; however, some AAACs still develop less sag than the equivalent soft ACSRs. In particular, Poplar develops 2.5 $\mathrm{m}$ sag, $0.5 \mathrm{~m}$ more sag due to creep, even though its performance is better than the equivalent soft ACSR (Jaguar).

The wood pole structure used for the $33 \mathrm{kV}$ OHL system is tall enough to preserve the minimum clearance from the ground even with an increase in sag values due to creep-strain effects. This increase reaches a maximum of $1 \mathrm{~m}$ for the AAACs and $0.5 \mathrm{~m}$ for the ACSRs, with the hard ACSRs developing slightly less creep than the soft ones. The electrical performance of the conductors discussed in previous sections remains the same as the electrical operating conditions have not changed. The increase of the maximum conductor operating temperature does not affect the creep considerably as long as it is below $75{ }^{\circ} \mathrm{C}$ and $100{ }^{\circ} \mathrm{C}$ for the AAACs and ACSRs respectively [4] as the maximum electrical loading occurs only for $1 \%$ of the 10 year operating time of the OHL.

On the contrary, the temperature at which EDT is applied influences the creep and the conductor sag considerably as it occurs $98 \%$ of the time, increasing further the difference between the initial and the 10 year sag of the conductors (Fig. 14). Therefore, by raising the everyday temperature the installed tension of the conductors erected on the OHL structure is increased along with the maximum mechanical loading as well as during the maximum electrical loading. This increase in tension results in a reduction of the sag that is developed during these loading conditions. However, it also results in an increase of creep-strain which, in turn, increases the sag values. Consequently, the reduction is approximately $50 \%$ less than the one expected. Furthermore, the increase in temperature at which EDT is applied affects only the conductors within the EDT zone as this is the limiting factor for MCT. 
It is also important to emphasize that this increase in temperature results in infringement of the self damping vibration limit of these conductors and therefore vibration dampers may be required. The EDT at $45{ }^{\circ} \mathrm{C}$ results in total cancelation of conductor self dumping vibration limit for the AAAC (Fig. 14) and therefore represents the sag of different AAAC conductors when the structure employs vibration dampers.

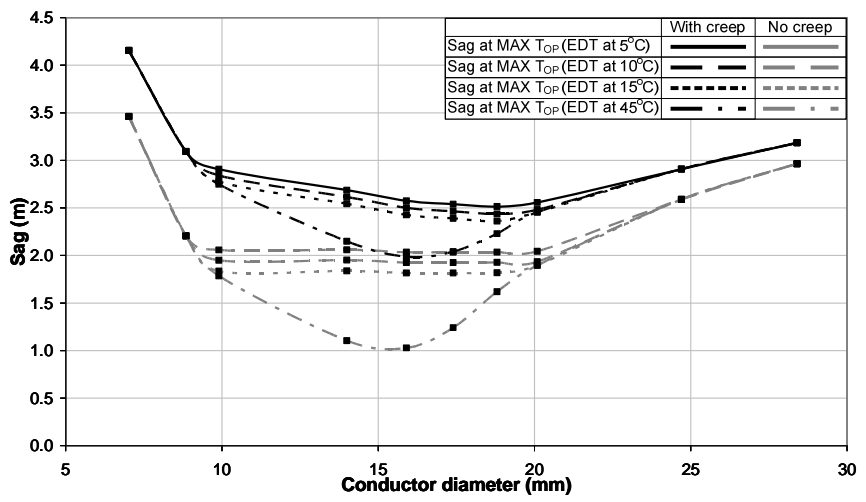

Fig. 14. Influence of the EDT temperature on the maximum electrical loading sag values for AAAC.

\section{Performance Comparison of HTLS Composite CONDUCTORS WITH AAAC}

\section{A. HTLS Composite Conductors}

The HTLS composite conductors that are used within this study are the recently developed Aluminium Conductor Composite Reinforced (ACCR) produced by $3 \mathrm{M}[16,17]$ and the Aluminium Conductor Composite Core Trapezoidal Wire (ACCC/TW) developed by Composite Technology Corporation (CTC) $[18,19]$. Both conductors can operate at high temperatures $\left(210{ }^{\circ} \mathrm{C}\right)$ without loosing mechanical strength and developing excessive sag; they differ however, in the technology and materials.

The ACCR conductor is an all aluminium conductor. This, consequently, keeps the structure of the conductor all conductive. Its outer wires have equivalent tensile strengths and stress-strain behavior to standard 1350-H19 aluminium wires and the core is made of metal matrix composite wires with each one having thousands of ultra-high-strength, micrometer-sized fibers fully embedded within aluminium of high-purity (Fig. 15) [17].

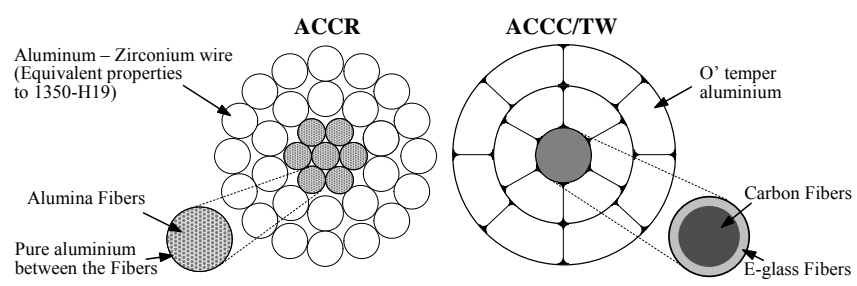

Fig. 15. Designs of ACCR and ACCC/TW composite conductors.

TABLE V

MCT AND SAG VALUES AT WeATHER AND ELECTRICAL LOADING CONDITIONS FOR THE COMPOSITE CONDUCTORS

\begin{tabular}{|c|c|c|c|c|c|c|c|c|c|c|c|}
\hline $\begin{array}{c}\text { Conductor Code } \\
\text { Name }\end{array}$ & $\begin{array}{c}\text { Diameter } \\
(\mathrm{mm})\end{array}$ & $\begin{array}{c}\text { Area } \\
\left(\mathrm{mm}^{2}\right)\end{array}$ & $\begin{array}{c}\mathrm{W}_{\mathrm{C}} \\
(\mathrm{kg} / \mathrm{km})\end{array}$ & $\begin{array}{c}\mathrm{RBS} \\
(\mathrm{kN})\end{array}$ & $\begin{array}{c}\mathrm{MCT} \\
(\mathrm{kN})\end{array}$ & $\begin{array}{c}\text { Sag-5.6 }{ }^{\circ} \mathrm{C} \\
(\mathrm{m})\end{array}$ & $\begin{array}{c}\mathrm{R}_{\mathrm{DC}-20}{ }^{\circ} \mathrm{C} \\
(\Omega / \mathrm{km})\end{array}$ & $\begin{array}{c}\mathrm{R}_{\mathrm{AC}-70{ }^{\circ} \mathrm{C}} \\
(\Omega / \mathrm{km})\end{array}$ & $\begin{array}{c}\mathrm{CT} \\
(\mathrm{kN})\end{array}$ & $\begin{array}{c}\mathrm{Sag}_{70}{ }^{\circ} \mathrm{C} \\
(\mathrm{m})\end{array}$ & $\begin{array}{c}\mathrm{I}_{\mathrm{MAX}} \\
(\mathrm{A})\end{array}$ \\
\hline LINNET-E & 18.3 & 246.4 & 656 & 72.51 & 20.866 & 1.44 & 0.128 & 0.1550 & 12.2 & 0.8 & 446 \\
\hline $336-T 16$ & 18.4 & 200 & 566 & 61.83 & 20.447 & 1.43 & 0.1595 & 0.1925 & 4.78 & 1.78 & 400 \\
\hline $397-T 16$ & 20.1 & 238.7 & 669 & 73.39 & 23.333 & 1.35 & 0.1338 & 0.1613 & 5.65 & 1.79 & 446 \\
\hline $477-T 16$ & 21.6 & 276.8 & 802 & 85.41 & 23.333 & 1.45 & 0.1153 & 0.1391 & 5.8 & 2.03 & 491 \\
\hline HAWK-E & 21.8 & 349.4 & 928 & 103.2 & 23.333 & 1.51 & 0.0903 & 0.1097 & 12.85 & 1.07 & 552 \\
\hline DOVE-E & 23.5 & 408.3 & 1083 & 122.33 & 23.333 & 1.64 & 0.0774 & 0.0943 & 12.61 & 1.27 & 607 \\
\hline 556-T16 & 23.9 & 338.1 & 937 & 102.75 & 23.333 & 1.59 & 0.0945 & 0.1140 & 6.22 & 2.31 & 551 \\
\hline GROSBEAK-E & 25.1 & 465.5 & 1238 & 135.23 & 23.333 & 1.76 & 0.0676 & 0.0826 & 12.3 & 1.49 & 658 \\
\hline 636-T16 & 25.2 & 374.8 & 1067 & 113.88 & 23.333 & 1.68 & 0.0851 & 0.1027 & 6.54 & 2.44 & 591 \\
\hline 795-T16 & 28.1 & 484.5 & 1333 & 143.24 & 23.333 & 1.94 & 0.0658 & 0.0795 & 7.5 & 2.74 & 689 \\
\hline DRAKE-E & 28.1 & 587.9 & 1555 & 182.82 & 23.333 & 2.01 & 0.0542 & 0.0665 & 12.18 & 1.9 & 753 \\
\hline
\end{tabular}

The ACCC/TW uses a carbon/E-glass fiber, polymer matrix composite non-metallic core as a strength member (Fig. 15) $[18,19]$. This increases its resistance for the same total conductor diameter since less conductive material is allocated to the same diameter. In order to address this, trapezoidal shaped, 63\% International Annealed Copper Standard (IACS) conductivity aluminium wires are used instead of 1350-H19 (61.2\% IACS) and 6201-T81 (52.5\% IACS) used for the ACCR and AAAC respectively [20].

\section{B. Performance Analysis of HTLS Composite Conductors at Maximum Loading Conditions}

The properties of ACCR and ACCC/TW conductors of different sizes and the computation results of their performance are shown in Table V. This allows for comparison with the equivalent AAACs of Table I at the maximum weather loading of the specified $33 \mathrm{kV}$ line. Smaller sizes are not developed by $3 \mathrm{M}$ and CTC while conductors of larger sizes are considered over-weighted for the weak wood pole structure and therefore, are not examined. 
The RBS of ACCC/TW is computed by considering only the strength of the composite core and not the aluminium wires [18].

Fig. 16 illustrates the sag values of the three different types of conductors at weather loading (continuous lines). Their sagging performance is very similar which is expected since the composite conductors are within the weak OHL zone (except of the 336-T16 and Linnet-E). The small variation of the results is caused by the differences in resultant conductor weight since the maximum permitted tension of the conductor is restricted by the OHL structure strength (Table V). Therefore, the increased RBS of the ACCC/TW conductors against the more or less equivalent in strength ACCR and AAAC results in no difference in their sagging performance when erected on the $33 \mathrm{kV}$ wood pole structure during the maximum mechanical loading of the OHL system.

When conductors are compared at the maximum electrical loading $\left(70{ }^{\circ} \mathrm{C}\right)$, the reduced coefficient of thermal expansion of HTLS composite conductors improves their sagging performance and therefore they sag less than the AAACs (Fig. 16). Furthermore, the performance of the ACCC/TW conductors at $70{ }^{\circ} \mathrm{C}$ is better than the one developed at $-5.6{ }^{\circ} \mathrm{C}$ which reveals that the elastic elongation of the conductor is larger than the thermal elongation. Therefore, their sag performance is influenced by the weather loading as this defines the minimum clearance to the ground. For the other types this happens during the electrical loading.

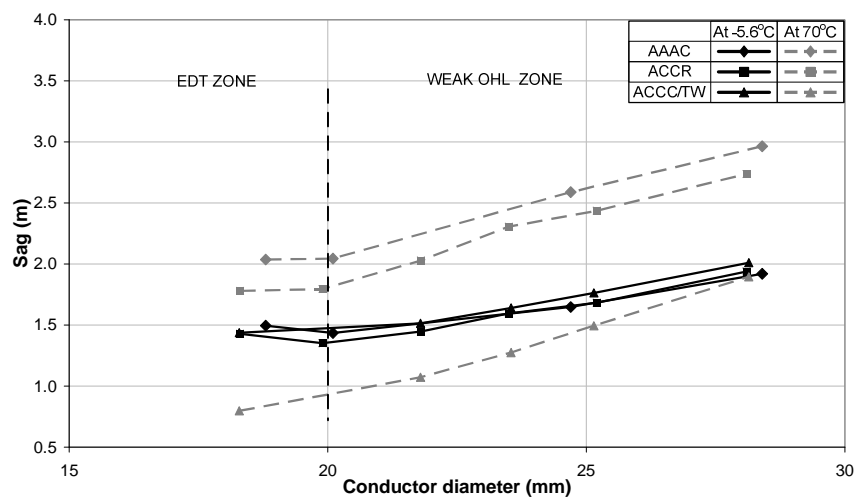

Fig. 16. ACCR and ACCC/TW sagging performance compared to AAAC at maximum weather and electrical conditions.

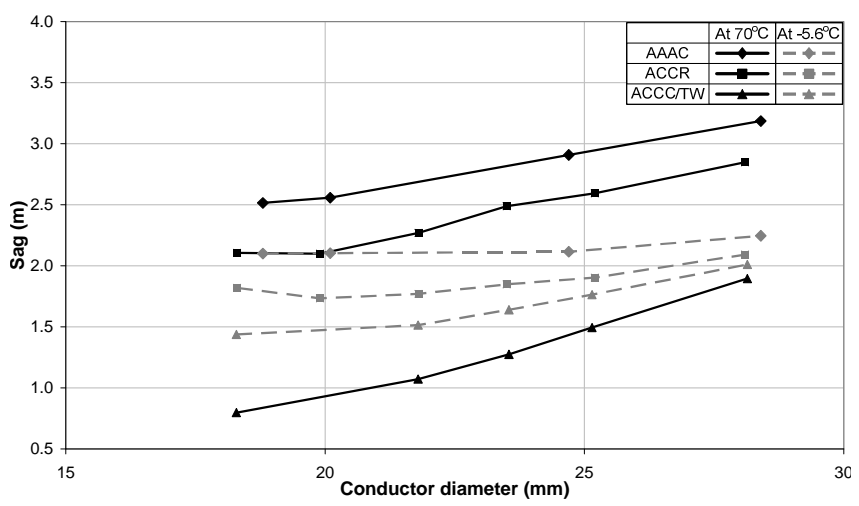

Fig. 17. 10 year creep effect on sag at the different critical loadings.
When the plastic elongation is considered in the computations, the performance of composite conductors is improved further when they are compared with the AAAC ones as they creep less (Fig. 17). In addition, since ACCC/TW conductors elongate only elastically [18], their performance is further improved compared to the ACCR ones.

The ampacity and losses of the ACCRs are similar to those of AAACs at $70{ }^{\circ} \mathrm{C}$ while ACCC/TWs allow approximately $12.5 \%$ more current flow at the same temperature (Fig. 18). This is caused by the reduction in ACCC/TWs electrical resistance (Tables II \& V).

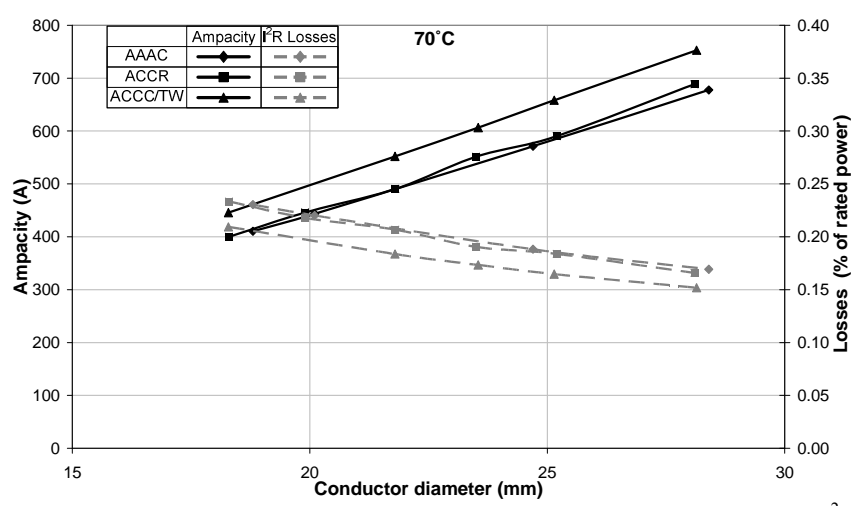

Fig. 18. Comparison of HTLS conductors with AAAC in ampacity and $\mathrm{I}^{2} \mathrm{R}$ losses.

\section{DISCUSSION}

The analysis of the sagging performance of conductors of different sizes on a particular structure indicated a classification of conductors into three zones. The boundaries of these zones are influenced by the conductor as well as the OHL structure. The conductor with the best electrical and mechanical performance was found to be the largest one within the EDT zone. However, the $33 \mathrm{kV}$ OHL structure of this study permits elevated sag values due to its height preserving the minimum clearance to the ground. This allows the installation of larger conductors that sag more but have better electrical performance.

AAAC conductors perform better than the ACSRs particularly when initial over-stressing is applied to negate the creep-strain effect. Soft ACSR conductors are in general heavier than the AAACs and this makes them less useful for comparatively weak wood pole structures, although their performance is not very different than that of AAACs. The weight of hard ACSRs dominates their behavior limiting their application, however, their increased strength can be useful when large spans are required.

The ACCR and ACCC/TW HTLS composite conductors develop $30 \mathrm{~cm}$ and $60 \mathrm{~cm}$ less sag than the AAACs, respectively, on the $33 \mathrm{kV}$ OHL when creep is not considered. When the 10-year creep is considered this reduction is further increased to $50 \mathrm{~cm}$ and $110 \mathrm{~cm}$, respectively. Considering that an $80 \mathrm{~cm}$ increase in clearance to the ground allows the voltage upgrade from $33 \mathrm{kV}$ to $66 \mathrm{kV}[3,21]$, then ACCC/TW could allow operation at $66 \mathrm{kV}$ when the 10 -year creep is 
considered. In the case of conductor initial over-tensioning, 20 $\mathrm{cm}$ taller insulators are required to avoid infringement of the minimum clearance. It is important to emphasize that the uprating in voltage of the OHL structure requires an increase of the separation of the conductors. However, the reduction in sag reduces the conductor blow out and this in turn can permit smaller separation distances of the phase conductors.

\section{VIII.CONCLUSIONS}

The analysis shows the importance of the OHL structure on the conductor's performance, which can be classified into three different zones. These zones define the conductors' sagging performance, which is the main factor that limits the clearance to the ground and consequently the conductors' ampacity.

The reduced thermal elongation coefficient is one of the greatest advantages that ACCR and ACCC/TW HTLS conductors offer on the $33 \mathrm{kV}$ OHLs. This reduction is considerable and increases the clearance to the ground to such a level that may allow voltage uprating of the OHL system to $66 \mathrm{kV}$ and therefore, increase the power transfer capacity of the OHL structure without increasing its operating temperature and, consequently, the $\mathrm{I}^{2} \mathrm{R}$ losses.

\section{ACKNOWLEDGEMENT}

This work is funded through the EPSRC Supergen V, UK Energy Infrastructure (AMPerES) grant in collaboration with UK electricity network operators working under Ofgem's Innovation Funding Incentive scheme; full details on http://www.supergen-amperes.org

\section{REFERENCES}

[1] K. Kopsidas, "Modelling Thermal Ratings of Arbitrary Overhead Line Systems", PhD Thesis, Dept. of Electrical and Electronic Engineering, The University of Manchester, Manchester, United Kingdom, 2009.

[2] "National Electrical Safety Code 2007 Edition," IEEE Std C2-2007, Aug. 2006.

[3] "BS EN 50423-3: Overhead electrical lines exceeding AC $1 \mathrm{kV}$ up to and including AC $45 \mathrm{kV}$ - Part 3: Set of National Normative Aspects," British Standards, 2005.

[4] "IEEE Guide for Determining the Effects of High-Temperature Operation on Conductors, Connectors, and Accessories," IEEE Standard 1283-2004, pp. 1-28, 2005

[5] "ENATS 43-93: Line Insulators," Energy Networks Association Technical Specifications, Issue 4, 2004

[6] "IEC 60815: Guide for the Selection of Insulators in Respect of Polluted Conditions," International Electrotechnical Commission, Jan 1986.

[7] "BS 3288-2: Insulator and Conductor fittings for overhead power lines Part 2: Specification for a range of fittings," British Standards, 1990.

[8] "ENATS 43-40: Single Circuit Overhead Lines on Wood Poles for Use at High Voltage Up to and Including 33kV," Energy Networks Association Technical Specifications, Issue 2, 2004.

[9] "BS EN 50423-1: Overhead electrical lines exceeding AC $1 \mathrm{kV}$ up to and including AC $45 \mathrm{kV}$ - Part 1: General requirements - Common specifications," British Standards, 2005.

[10] "ASTM B 230/B 230M-99: Specification for Aluminum 1350-H19 Wire for Electrical Purposes," Annual Book of ASTM Standards, vol. 02.03, pp. 91-94, 2005.
[11] "ASTM B 398/B 398M-02: Standard Specification for Aluminum-Alloy 6201-T81 Wire for Electrical Purposes," Annual Book of ASTM Standards, vol. 02.03, pp. 178-181, 2005.

[12] "ASTM B 779-03: Standard Specification for Shaped Wire Compact Concentric-Lay-Stranded Aluminum Conductors, Steel-Reinforced (ACSR/TW)," Annual Book of ASTM Standards, vol. 02.03, pp. 309-314, 2005.

[13] "IEEE Standard for Calculating the Current-Temperature of Bare Overhead Conductors," IEEE Std. 738-2006 (Revision of IEEE Std 7381993), pp. 1-59, 2007.

[14] "CIGRE SC22 - WG05: A practical method of conductor creep determination," Electra $N^{\circ} 24$, pp. 105-137, 1974.

[15] "CIGRE SC22 - WG05: Permanent elongation of conductors. Predictor equation and evaluation methods," Electra $N^{\circ} 75$, pp. 63-98, 1981.

[16] Aluminum Conductor Composite Reinforced Technical Notebook (477 kcmil family) Conductor \& Accessory Testing, 2006, 3M.

[17] Aluminum Conductor Composite Reinforced Technical Notebook (795 kcmil family) Conductor \& Accessory Testing, 2003, 3M.

[18] A. Alawar, E. J. Bosze, and S. R. Nutt, "A composite core conductor for low sag at high temperatures," IEEE Transactions on Power Delivery, vol. 20, pp. 2193-2199, 2005.

[19] "Trapezoidal Aluminum Conductor Composite Core Concentric-LayStranded," [Online], Available at: http://www.generalcable.com/ R/rdonlyres/E89EB79-4A3F-4B2C-9E89-72CD85FD2207/0/ TY0023R0406.pdf, General Cables BICC Brand Energy, [Online document], [cited 2007 Jan. 24].

[20] "ASTM B 193-02: Test Method for Resistivity of Electrical Conductor Materials," Annual Book of ASTM Standards, vol. 02.03, pp. 68-72, 2005.

[21] "ENATS 43-8: Overhead Line Clearances," Energy Networks Association Technical Specification, Issue 3, 2004

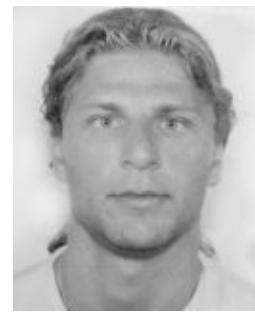

Konstantinos Kopsidas was born in Lefkas, Greece in 1977. He received his Higher Technological Education degree in Electrical Engineering from Institute of Piraeus (Athens) in 2002 and a Class I BEng (Hons) in Electrical \& Electronic Engineering from UMIST in 2004. He completed his MSc with distinction in Electrical Power Engineering at The University of Manchester in 2005. He is, currently, a research assistant and a $\mathrm{PhD}$ student in the same University. He was awarded the Scottish Power 'Power Learning Award' as well as the course prize twice.

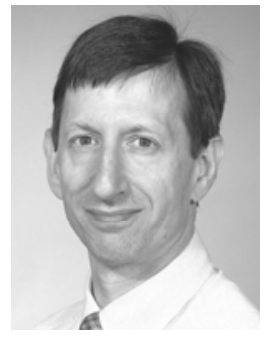

Simon M. Rowland (SM'07) was born in London, England. He completed his B.Sc. degree in Physics at UEA and his Ph.D. degree at London University. He was awarded the IEE Duddell Premium in 1994 and became a FIEE in 2000. He has worked for many years on dielectrics and their applications. He has also been Operations and Technical Director in a multinational manufacturing company. He joined The School of Electrical and Electronic Engineering in The University of Manchester as a Senior Lecturer in 2003. 